\title{
ENTRE OS DITOS E OS INTERDITOS: REPRESENTAÇÕES DE PROFESSORES E PROFESSORAS DO ENSINO FUNDA- MENTAL SOBRE GÊNERO E SEXUALIDADE
}

\author{
BETWEEN SAID AND PROHIBITED: representations of teachers and teaching of \\ elementary education on gender and sexuality \\ ENTRE DICHO Y PROHIBIDOS: representaciones de los maestros y maestras de \\ la enseñanza de la educación primaria sobre el género y la sexualidad
}

\begin{abstract}
Jonas Alves da Silva Junior Professor Doutor da Universidade Federal Rural do Rio de Janeiro (UFRRJ). jonasjr@usp.br
\end{abstract}

Mônica Pinheiro Fernandes Professora Doutora da Universidade Federal Rural do Rio de Janeiro (UFRRJ). monicapinheiro@uol.com.br

Sandra Regina de Oliveira Faustino Professora Mestre da Secretaria de Educação do Município de Duque de Caxias - RJ. sanre60@hotmail.com

\begin{abstract}
RESUMO: Este artigo é fruto de entrelaçamentos de vivências advindas do trabalho realizado no PIBID/UFRRJ e da investigação sobre as representações de professores/as do Ensino Fundamental de uma escola municipal de Queimados/RJ no que concerne a gênero e sexualidade, desenvolvida pelo Grupo de Pesquisa Infâncias até os 10 anos (GRUPIs). Esta pesquisa adotou o método exploratório-qualitativo para produzir reflexões e conhecimentos de uso mais efetivo no âmbito das representações sociais sobre gênero e sexualidade. Para atingir o nosso objetivo, valemo-nos de teóricos que estudam sobre formação de professores, bem como os que pesquisam sobre gênero e sexualidade e das respostas obtidas com base no questionário aplicado aos professores da escola-campo. As reflexões resultantes das discussões relativas à pesquisa com os/as professores/as revelaram representações carregadas de preconceitos e ambiguidades, urgindo como guisa de conclusão a necessidade de abordar os temas gênero e sexualidade no currículo de formação inicial e continuada dos/as educadores/as, com o intuito de enfrentar e desconstruir preconceitos de forma criativa, crítica e dialógica. Devido à complexidade e urgência do tema, a investigação apontou para continuidade e aprofundamento de estudos sobre gênero e sexualidade na escola.
\end{abstract}

PALAVRAS-CHAVE: Gênero. Sexualidade. Representação social. PIBID. Formação de professores.

ABSTRACT: This article is the result of entanglements of resulting experiences from work carried out PIBID / UFR$\mathrm{RJ}$ and research on the representations of elementary school teachers from a municipal school in Queimados / RJ with regard to gender and sexuality developed by childhoods Research Group up 10 years (GRUPIs). This research adopted the exploratory qualitative method to produce ideas and knowledge more effective use within the social representations of gender and sexuality. To achieve our goal, we make use of theorists who study on teacher training, as well as researching on gender and sexuality, and the answers obtained based on the questionnaire administered to school-field teachers. The reflections resulting from discussions concerning the survey of teachers showed charged representations of prejudices and ambiguities, urging as a way of conclusion the need to address the issues gender and sexuality in the curriculum of initial and continuing training of teachers, in order to confront and deconstruct prejudices of creative, critical and dialogical way. Due to the complexity and urgency of the issue, the investigation pointed to continuing and deepening studies on gender and sexuality at school.

KEYWORDS: Gender. Sexuality. Social representation. PIBID. Teacher training.

$\overline{\text { Artigo recebido em janeiro de } 2016}$

Aprovado em março de 2016 
RESUMEN: Este artículo es el resultado de los entrelazamiento de vivencias adviniendo del trabajo llevado a cabo por el PIBID / UFRRJ y de la investigación sobre las representaciones de los profesores de la escuela primaria de una escuela municipal en Queimados / RJ, con respecto al género y la sexualidad desarrollada por infancias Grupo de Investigación hasta los 10 años (GRUPIs). Esta investigación adoptó el método cualitativo exploratorio para producir ideas y conocimientos uso más eficaz dentro de las representaciones sociales de género y la sexualidad. Para lograr nuestro objetivo, hicimos uso de los teóricos que estudian en la formación del profesorado, así como la investigación sobre el género y la sexualidad, y las respuestas obtenidas en base al cuestionario aplicado a los docentes de campo de la escuela. Las reflexiones resultantes de los debates relativos a la encuesta de los profesores mostrarán representaciones de los prejuicios y las ambigüedades, lo que necesita como una manera de conclusión, en la necesidad de abordar cuestiones de género y la sexualidad en el currículo de la formación inicial y continua de los docentes, con el fin de enfrentar y deconstruir prejuicios de manera creativa, crítica y dialógica. Debido a la complejidad y la urgencia de la cuestión, la investigación apuntó a continuar y profundizar los estudios sobre género y sexualidad en la escuela.

PALABRAS CLAVE: Género. Sexualidad. Representación Social. PIBID. La formación del Profesorado. 


\section{1| INTRODUÇÃO}

Este artigo tem por alicerce experiências advindas da participação no Programa Institucional de Bolsa de Iniciação à Docência (PIBID) e das investigações pautadas na diversidade e inclusão nas escolas públicas realizadas pelo grupo de pesquisa Infâncias até os 10 (dez) anos (GRUPIs/ UFRRJ/CNPq). Essas vivências ecoaram e se desdobraram nesta pesquisa que se justifica, fundamentalmente, na compreensão de que a investigação das representações sociais e sua respectiva influência sobre a prática pedagógica permitem aos/às professores/as a tomada de consciência indispensável à revisão e recriação de sua conduta pedagógica diária, por meio do remodelamento do significado da história profissional e pessoal.

Outra justificativa para a concretização deste estudo, decorrente da anterior, conecta-se à admissão de sua relevância para as possíveis transformações na prática pedagógica do/a professor/a, o que é esperado quando se aspira conceber uma escola inclusiva e democrática. As instâncias sociais responsáveis pelas mutações nas representações são os meios de comunicação, a religião, a Ciência, a política, a instituição escolar e os sujeitos que participam dessas instituições, compostos, em sua maioria, por especialistas que disseminam e alastram representações que irão influenciar, transformar ou modernizá-las. Na escola, por exemplo, os/ as educadores/as ressignificam suas representações no cotidiano escolar. Esse mecanismo construirá, atualizará ou mesmo transformará as representações dos/as educandos/as. Por isso, considera-se esse fator de vital relevância na investigação da escola como um lugar que não é imparcial, especialmente no que se refere à sexualidade e às relações de gênero.

Durante a etapa em que foi desenvolvido o projeto referente ao subgrupo PEDiversidade ${ }^{1}$ na escola-campo, em Queimados/RJ, foi possibilitada a articulação entre a formação inicial e continuada de professores, via PIBID, com a pesquisa sobre a representação dos/as professores/ as dos anos iniciais do Ensino Fundamental sobre gênero e sexualidade, via GRUPIs. Nessa perspectiva, a relevância da articulação entre formação inicial e continuada de professores/as refere-se à construção de táticas de superação do sexismo, homofobia e da heteronormatividade, com base na interação entre bolsistas PIBID (que estão na fase inicial de sua formação para a docência) e docentes (em processo de formação contínua), propiciando a abertura de um espaço de debate e desconstrução dos alicerces afetivos dos preconceitos.

Para realizarmos tal intento criamos uma rede de conexão entre formação inicial de professores e conceitos sobre gênero e sexualidade amparados em bibliografias para, posteriormente, refletirmos sobre as representações sobre gênero e sexualidade dos/as professores/as.

Este trabalho foi realizado no contexto da rede pública de educação, no intuito de verificar os processos de construção de subjetividades, relacionados com a instituição de verdades conduzidas por discursos que se encontram articulados a programas oficiais e que se prestam a inserir o tema da sexualidade no espaço escolar. Procuramos refletir sobre as implicações dos discursos das políticas públicas acerca da educação sexual, como um discurso contemporâneo que está sendo indicado para a educação, principalmente, através de diretrizes curriculares, como os Parâmetros Curriculares Nacionais e os Referenciais Curriculares Nacionais para a Educação Infantil. Focamos a análise nas práticas instaladas no cotidiano escolar, buscando entender suas

\footnotetext{
${ }^{1}$ Trata-se de um subgrupo dentro do subprojeto PIBID Interdisciplinar do Instituto Multidisciplinar (UFRRJ), cujas áreas (Pedagogia, Letras e Matemática) estão articuladas em torno de processos de letramentos diversos. No caso do grupo de Pedagogia Diversidade (PEDiversidade), a tônica é o trabalho com base na didática intercultural utilizando-se como recurso pedagógico literatura infantil, curtas metragens de animação e outras formas de manifestações artísticas.
} 
lógicas e efeitos, principalmente no que diz respeito à proposição de uma educação inclusiva e não sexista.

Desde as décadas de 1960 e 1970, expressivas mudanças socioculturais e históricas ocorreram, no que se refere às relações de gênero e sexualidade, a partir da atuação dos movimentos feminista, gay e lésbico, que se propuseram a defender de forma mais aberta e contundente suas exigências e contendas, bem como do aparecimento, na década de 1980, da AIDS. Nessa perspectiva, novas maneiras de arquitetar e experienciar as identidades sexuais e de gênero são conjeturadas, com desdobramentos na esfera social e política (através das ONG, da militância político-partidária, das políticas públicas) e, na esfera acadêmica, com a efetivação de estudos nos vários campos do saber. Esses campos têm direcionado seu foco para sexualidade e para as relações de gênero como fenômenos "construídos", expandindo a discussão para outros aspectos, como o corpo, as identidades etc.

No que tange à Educação, nota-se a inclusão desses assuntos nos currículos, sobretudo a partir da década de 1990, quando os espaços escolares são "conclamados" a lidar com os pressupostos e conexões que abarcam sexualidade e gêneros. Todavia, o tratamento a essas temáticas nas aulas limitou-se à "biologização" da sexualidade e do sexo, ao priorizar, simples e unicamente, conteúdos formais concernentes à reprodução e à prevenção de DST (doenças sexualmente transmissíveis).

A densidade da sexualidade humana, bem como a legitimação da existência de uma diversidade sexual foram sumariamente rejeitadas na escola, acarretando discriminação e marginalização de alunos/as que não se encaixam nos protótipos heterossexistas valorizados socialmente. Assim, nesta pesquisa, investigamos as representações de professores/as de uma escola pública do município de Queimados (RJ), buscando desvendar concepções e crenças em relação a gênero e sexualidade no cotidiano escolar, almejando um maior aprofundamento teórico, metodológico e interpretativo.

O objetivo da pesquisa é analisar as representações dos sujeitos para responder às seguintes questões norteadoras: (a) como e sob que justificativas o preconceito à diversidade sexual se estabelece nas representações de professores e professoras? (b) o tema diversidade sexual é importante na formação inicial e continuada de professores/as?

Neste trabalho estamos nos propondo a pensar as produções de representações como construtoras de discursos e práticas. Desta forma, buscamos iluminar as condições de possibilidade de emergência de discursos e práticas constituintes de regimes de verdade que constituem as subjetividades dos sujeitos. Discursos estes que se traduzem contraditórios, paradoxais e que não são recebidos de maneira passiva pelos indivíduos. Assim, para dar conta dos objetivos propostos neste artigo, trouxemos uma discussão teórica acerca da formação de professores no âmbito da educação em sexualidade (sessão 2), na qual pontuamos a importância do debate sobre gênero e sexualidade em cursos de licenciatura e em programas educacionais, como o PIBID. Na sessão seguinte (3), após apresentarmos a metodologia, buscamos explicitar os pressupostos teóricos das representações sociais, bem como suas contribuições para a pesquisa em Educação. É nesta sessão em que os dados da pesquisa empírica são apresentados e analisados.

Passamos, agora, à apresentação dos fundamentos teóricos. Afinal, não há pesquisa sem a adoção de uma orientação teórica, sem o reconhecimento dos pressupostos filosóficos que estão na base e nas entrelinhas do esforço interpretativo. Esforço para conferir sentidos e relevância aos indicadores empíricos produzidos na interação entre pesquisador/a e os fenômenos investigados. 


\title{
2 | FORMAÇÃO DE PROFESSORES NO ÂMBITO DA EDUCAÇÃO EM SEXUALIDADE
}

Frente a essa dimensão de precariedades, é relevante pontuarmos algumas reflexões sobre a formação de professores que persiste há décadas como desafio para o governo brasileiro. Sobre isso, novos rumos foram traçados a partir da Conferência Mundial sobre Educação para Todos, realizada em Jomtien, Tailândia, em 1990, que influenciou decisivamente as políticas educacionais dos países em desenvolvimento, dentre eles o Brasil.

Estas orientações nortearam a Lei de Diretrizes e Bases da Educação Nacional (LDBEN), Lei $n^{\circ}$ 9.394/96, no que se refere à formação docente para atuar na Educação Básica, prevendo, como princípio orientador dessa formação a "associação entre teorias e práticas, inclusive mediante a capacitação em serviço" e o "aproveitamento da formação e experiências anteriores em instituições de ensino e outras atividades" (BRASIL, 1996, p. 13), Após a promulgação da LDBEN foram intensificadas as políticas de formação de professores. Segundo Freitas:

A configuração da formação de professores em nosso país respondeu ao modelo de expansão do ensino superior implementado na década de 1990, no âmbito das reformas do Estado e subordinado às recomendações dos organismos internacionais. No âmbito da formação, caracteriza-se pela criação dos Institutos Superiores de Educação e pela diversificação e flexibilização da oferta dos cursos de formação - normais superiores, pedagogia, licenciaturas, cursos especiais e cursos à distância -, de modo a atender a crescente demanda pela formação superior. (FREITAS, 2007, p. 1208).

\begin{abstract}
A reflexão acima salienta a dinâmica de profissionalização docente. Em acordo com as reformas do Estado, a profissão docente passa a ser um caminho possível para ampliação de um mercado de formação, bem como ganha destaque no âmbito educacional podendo ser configurada como um caminho para o empowerment (empoderamento) da categoria, ou seja, para torná-los mais autônomos e responsáveis pelo andamento dos trabalhos na escola. Apoiamo-nos, pois, na compreensão de uma formação alinhada com o fortalecimento profissional dos professores, para que seja necessário elevar o grau de sua formação de modo a introduzi-los/as em valores, práticas e conhecimentos acadêmico-científicos.
\end{abstract}

Neste contexto, no ano de 2007, ocorre a criação do PIBID nas Instituições de Ensino Superior. A ideia central do programa é proporcionar às escolas de educação básica o protagonismo nos processos de formação dos estudantes de licenciatura, bem como dos professores experientes, que podem atuar como co-formadores desses futuros docentes.

Na perspectiva do PIBID e, mais especificamente, da proposta do subgrupo PEDiversidade, pudemos refletir sobre o termo gênero como sendo empregado "para descrever a diferenciação social entre homens e mulheres" e o termo sexualidade "como uma descrição geral para a séries de crenças, comportamentos, relações e identidades socialmente construídas e historicamente modeladas (WEEKS, 2001, p. 43). Essas reflexões nos impulsionaram a investigar as representações dos/ as professores/as da escola-campo sobre gênero e sexualidade, a fim de problematizarmos essa relação nas suas práticas educativas, buscando o diálogo permanente entre pessoas consideradas autores de vida, enquanto sujeitos que participam ativamente na construção de conhecimento.

No âmbito dos Estudos de Gênero e Sexualidade na formação inicial/continuada de professores/as, um passo relevante que tem sido dado no domínio das universidades é a tentativa de concretizar os núcleos de pesquisa sobre direitos e cidadania LGBT e das mulheres. E, neste sentido, mesmo que se estruturando sob muitas adversidades e tendo que enfrentar a homofobia articulada a concepções ideológicas que infringem as meritocracias, o PIBID tem contribuído na construção de uma memória da subordinação de sexualidades dissidentes, uma vez que, geralmente na 
história não foram encontradas alusões capazes de reconhecimento positivo. Essa contribuição tem sido construída por meio de subprojetos que tratam sobre gênero e sexualidade no espaço escolar de maneira a introduzir a temática na discussão com alunos/as por meio de diversificadas atividades pedagógicas.

No contexto social, a escola tem se configurado como um espaço de grandiosa importância na normalização e manutenção da heterossexualidade e dos rígidos modelos fixadores dos gêneros masculino e feminino em nossa sociedade (GARCIA, 2015). Para exemplificar, junto à família, tem atuado por meio da preponderância que determina a institucionalização do casamento (historicamente avalizado a esta parcela populacional - heterossexuais - peculiares direitos civis, como os de herança e previdenciário). Nos últimos anos, em nosso país, tem aumentado a luta política pela expansão desses direitos para gays e lésbicas, mediante a aprovação do denominado "Projeto de Parceria Civil Registrada" (principalmente, da admissão das uniões afetivas entre homossexuais). A inexistência de leis que assegure os direitos a gays, lésbicas e travestis, assim como a limitada perspectiva social e curricular a respeito da abrangência do conceito de família elucida como a heteronormatividade dificulta o acesso dos ditos "transgressores" à cidadania plena, com base na força a ela atribuída pelos coligados poderes público, jurídico e educacional.

Toda representação, seja ela hegemônica ou contra-hegemônica, repercute paradigmas que são produzidos, discursivamente, por meio da linguagem. No cerne desse processo de formação das diferenças, o currículo escolar, fabrica instrumentos particulares de conhecimento, significações sociais e identidades culturais (de gênero, classe, sexualidade, raça, etnia, geração) e emerge como espaço de significação, perpassado por processos que asseguram não apenas a representação de uma identidade, mas também o fato de incluí-la ou excluí-la por conta dos jogos de interesse que acontecem por disputa de poder (GARCIA, 2015; SEFTON, 2013; RIZZATO, 2013).

Interessa-nos evidenciar que a sexualidade, enquanto princípio humano, não deve ser minimizado a um artefato excêntrico, fora do indivíduo, sobre o qual se profere um discurso técnico, insensível e doutrinário. Enquanto marca proeminente da subjetividade, da existência, e ainda mais se se considerar os enquadramentos e controles religiosos e históricos justapostos, a sexualidade, sob a perspectiva da construção social, só pode ser abordada de modo intensamente contíguo, impingido de probidade e humanismo, para ser eficiente e expressiva.

Isto quer dizer que uma das possibilidades para o fortalecimento da educação sexual está na perspectiva binária: de um lado, crítica a todas as construções, definições e arquétipos históricos e sociais, que abarcam proibições, tabus e preconceitos; e de outro, o subjetivo, o afetivo, o existencial, que a educação tradicional aspira refrear num discurso objetivo, supostamente neutro, e remoto. Ao/à professor/a resta o desafio de descobrir a maneira imparcial de conduzir este paradoxo de modo coeso e coerente.

A sexualidade, na contemporaneidade, passa a ter maior relevância e preocupação entre os/as educadores/as, pois, na proporção em que todos os estratos da sociedade se veem abalizados pela invocação a uma sexualidade consumista e narcisista, ou seja, assinalados pela procura individual de uma forma de prazer, esta marca surge em qualquer esfera que realmente se comprometa a educar, ou desvelar criticamente toda a cultura humana. Todavia, além de ser um assunto muito polêmico é, ainda, tabu no espaço escolar. As recentes pesquisas na área apontam que o trabalho com gênero e sexualidade na escola está submersa numa cortina sombria, carregada de culpas, incertezas, incoerências, castigos e coerções (GARCIA, 2015; SANTOS, 2014; ZARTH, 2013; OLIVEIRA, 2010). A instituição escolar desempenha muitas vezes, uma nuança nebulosa e ríspida e em outras um matiz multicolorido e fecundo, no que tange à sexualidade humana. Foi nesta trama de relações, entre o dito e o interdito, engendrados no ambiente escolar, que esta investigação foi concebida. 
Por conta de tais adversidades e incoerências, a questão da sexualidade, na atualidade, adquire cada vez mais relevância dentro e fora dos muros escolares. É preocupação de muitos/ as educadores/as e profissionais de outras áreas que investigam, registram e divulgam debates sobre o tema. O Ministério da Educação o preceitua nos parâmetros nacionais (PCN) para que todas as escolas possam ter acesso e possibilidades de se envolverem com o tema. Os meios de comunicação de massa se valem da oportunidade para vicejar informações a respeito de sexo, de modo que todos tenham a capacidade de lidar com distintos mecanismos de abordagem e discussão acerca dessa problemática.

Percebe-se, superficialmente, com isso, que a abertura do tema no ambiente escolar está aplainada. Entretanto isso não é verdade, porque o assunto permanece aramado de coerção, dúvidas, enigmas, temores, inquietações e, por que não dizer, provocações, nos debates com professores/as e demais profissionais da educação, mas, sobretudo, com crianças e adolescentes no espaço escolar (BALESTRIN, 2007). É certo que a sociedade brasileira por muito tempo permaneceu praticamente imóvel perante uma demanda social tão importante quanto esta: sexualidade. Diversas crianças e adolescentes continuam a aprender e a ensinar umas às outras sobre temas entendidos como tabus, dentre eles a masturbação, virgindade, primeira relação sexual, métodos contraceptivos e homossexualidade. $O$ fato é que as escolas oferecem certos obstáculos em inserir tópicos concernentes à educação sexual e essa relutância é intensificada na quase totalidade das instituições quando a problemática invade o território da diversidade sexual.

Organizados por um conjunto de professores/as e pesquisadores/as e lançados pela Secretaria de Educação Fundamental do Ministério da Educação, a partir de 1997, os Parâmetros Curriculares Nacionais (PCN) são publicações constantes em quase todas as escolas públicas, os quais tem por finalidade nortear os/as professores/as na estruturação dos conteúdos curriculares e propõem temas transversais, que estão atrelados ao dia-a-dia da maioria das pessoas. Além do currículo constituído pelas disciplinas da grade convencional, os PCN propõem os temas transversais, que seriam adaptados à realidade social de cada comunidade, a saber: ética, meio ambiente, pluralidade cultural, trabalho e consumo, saúde e orientação sexual.

De acordo com os estudos de Vianna e Unbehaum (2004), a despeito de se assentar apenas como um parâmetro e, logo, não se estabelecendo como uma diretriz obrigatória, os PCN ambicionam instituir uma meta educacional, para a qual devem concorrer as ações políticas do MEC, tais como as atinentes aos projetos destinados à formação inicial e continuada de profissionais da educação, à crítica e aquisição de livros e outros materiais didáticos e à avaliação institucional (VIANNA; UNBEHAUM, 2004, p. 89).

Ao cotejar formação inicial e continuada de professores/as, que se pratica no Brasil, com a questão da sexualidade, permanece a dúvida se esses educadores estariam aptos e/ou suscetíveis a debater e organizar uma sequência de atividades transversais estruturadas e conduzidas a uma finalidade específica. Tome-se, por exemplo, o tema 'Orientação Sexual' (PCN). Para ministrá-lo, de maneira a acatar as orientações oficiais, o/a professor/a versaria sobre fundamentos éticos, jurídicos, religiosos, sociológicos, históricos, psicológicos, antropológicos e pedagógicos; levaria em consideração a linguagem e suas representações, ao priorizar os sentidos da complexidade do país. Os/as professores/as, entretanto, a despeito de se sensibilizarem em relação à urgência de legitimar uma maior abertura para a abordagem das questões referentes à sexualidade na escola, permanecem sem contribuições apropriadas para lidar com esses assuntos. Destarte, na maioria das vezes, terminam por restringi-la a um tratamento integralmente biologizante, que tem o papel de resguardar o/a educador frente aos/às alunos/as, e no que se refere às suas próprias incertezas, medos e aflições. 
Alguns estudos como os de Garcia (2015), Rizzato (2013) e Santos (2014) trazem à baila o despreparo dos/as educadores/as e demais profissionais da educação para atuar com a sexualidade na escola, uma vez que não tiveram contato com o tema, nem na formação inicial, nem na continuada. Rizzato (2013) afiança que entende as dificuldades relacionadas com a inclusão de assuntos ligados à sexualidade, educação sexual e às relações de gênero na escola, porque a maioria dos espaços de formação - incluindo as universidades - ainda lutam contra a inserção destes temas nos cursos de licenciatura, razão pela qual fica a cargo da formação continuada que nem sempre acontece - a responsabilidade de completar esta lacuna.

\section{3 | REFLETINDO SOBRE AS REPRESENTAÇÕES DOS PROFESSORES DO ENSINO FUN- DAMENTAL SOBRE GÊNERO E SEXUALIDADE}

Para refletir a respeito das representações sobre gênero e sexualidade dos/as professores/as dos anos iniciais do Ensino Fundamental da escola-campo, em Queimados/RJ, decidimos organizar nosso percurso investigativo, trilhando um caminho metodológico que nos auxiliaram durante esta jornada.

\subsection{Nossos passos iniciais}

O percurso iniciou após a aplicação de questionário, com perguntas abertas e fechadas, respondidas por 11 (onze) professores/as da escola-campo. Trata-se de uma pesquisa de cunho qualitativa, cujo intento é sistematizar e analisar as representações sociais de professores/as do primeiro segmento do Ensino Fundamental sobre gênero, sexualidade e práticas relacionadas à Educação Sexual nas aulas. Escolheu-se o questionário como instrumento de pesquisa, por se tratar de tema ainda considerado tabu e de difícil diálogo no cotidiano escolar. Assim, concluímos que, por meio de questões abertas e fechadas, sendo totalmente garantido o anonimato, os sujeitos participantes ficariam mais à vontade e seguros para narrarem, por meio da escrita, o que Ihes conviessem.

Cabe esclarecer que o questionário aplicado é parte integrante da pesquisa "Representações de Professores/as da Educação Infantil e do Ensino Fundamental I sobre Sexualidade e Educação Sexual", vinculada ao grupo de pesquisa "Infâncias até os 10 anos (GRUPI's/UFRRJ/CNPq)", pelo viés da linha de pesquisa "Sexualidade, Gênero, Infância e Educação". Faz parte também, de um dos objetivos do PEDiversidade, que é investigar práticas e representações dos/as professores/ as sobre diversidade na escola.

\subsection{Nossos passos reflexivos para compreendermos os conceitos de gênero e sexual- idade}

O Brasil é uma sociedade multiétnica com imensa diversidade de culturas vindas de povos que introduziram costumes, valores, tradições, línguas, religiosidades, entre outros aspectos que constituem nossas identidades sociais - as quais são passíveis de diferentes interpretações econômicas, políticas, educacionais e sociológicas. Dentro deste contexto e buscando a interpretação para o campo educacional que nos possibilite compreender as colocações dos/as professores/as que responderam ao questionário recorremos a estudiosos como Foucault, Louro, Weeks, dentre outros, para trilhar nosso caminho.

Se contemplarmos minuciosamente a história, veremos que a sexualidade sempre foi assentada em discurso como alvo de contínua inquietação. Em seu livro "História da sexualidade", Foucault 
(2007) já alegava que desde o século XVIII o sexo tem aguçado um tipo de erotismo discursivo generalizado. Com o surgimento da AIDS e com os alarmantes índices de gravidez na adolescência, as políticas públicas começaram a se movimentar em torno de programas de prevenção, na expectativa de amenizar tais problemas. Todavia, no contexto escolar, é possível notar alguns esforços no que tange à discussão da sexualidade, mas muitas vezes este assunto é tratado apenas sob o viés da prevenção, do medo da doença e da morte, adicionado a uma certa apreensão moral. A visão é quase sempre biológica (ensina-se a anatomia dos órgãos sexuais, como se configura a fecundação, o nascimento, os métodos contraceptivos, bem como as táticas de prevenção das doenças sexualmente transmissíveis). Outros fatores que favorecem esta discussão são as ideias que fazem menção à relação entre corpo e sexualidade apresentadas por Weeks (2001, p. 38):

embora o corpo biológico seja o local da sexualidade, estabelecendo os limites daquilo que é sexualmente possível, a sexualidade é mais do que simplesmente o corpo [...] A sexualidade tem tanto a ver com nossas crenças, ideologias e imaginações quanto com nosso corpo físico.

O pesquisador aduz tendo como base o pressuposto de que "os corpos não têm nenhum sentido intrínseco e que a melhor maneira de compreender a sexualidade é como um construto histórico" (WEEKS, 2001, p. 39). Sexualidade, então, não se restringe ao aspecto genital e à reprodução, envolve a dimensão do prazer, da subjetividade e da intersubjetividade. Está inserida no social e na cultura, da qual a dimensão de gênero deve ser levada em consideração. Por isso, ao se debater com meticulosidade o conceito de gênero, chegar-se-á a pesquisadores das Ciências Sociais como Scott, e dos teóricos pós-estruturalistas. O vocábulo "gênero" começou a ser registrado e disseminado no movimento feminista da década de 1970. "As feministas começam a utilizar a palavra 'gênero' mais seriamente, num sentido mais literal, como uma maneira de se referir à organização social da relação entre os sexos” (SCOTT, 1990, p. 5). As mulheres proporcionaram notoriedade a esse conceito que é resultado de movimentos da emancipação feminina, contra a opressão. E é nessa conjuntura que, por exemplo, a discussão do conceito de gênero surge com mais intensidade.

As abordagens feministas pós-estruturalistas se arredam daquelas concepções que interpretam o corpo como uma instituição biológica universal para investigá-lo como um constructo sociocultural e linguístico, fruto e efeito das relações de poder. Nesse aspecto, o conceito de gênero passa a incorporar as matizes de construção social, cultural e linguística encalacradas com os processos que distinguem mulheres de homens, ao incluir aquelas tecnologias que determinam seus corpos, diferenciando-os e apartando-os como corpos dotados de sexo, gênero e sexualidade. O conceito de gênero prioriza, justamente, a análise dos processos de constituição dessas distinções - biológicas, comportamentais ou psíquicas - instituídas entre homens e mulheres; por isso, ele nos desvia de abordagens que propendem apenas à focalização de papeis e funções de mulheres e homens para aproximar-se de tratamentos muito mais amplos, levando a acreditar que as próprias instituições, os símbolos, as regras, os saberes, as leis, os comportamentos e políticas de uma sociedade são instauradas e perpassadas por representações e desígnios de feminino e de masculino e, concomitantemente, constroem e/ou ressignificam essas representações (ANDRADE, 2015; MEYER, 2003; LOURO, 1998; SCOTT, 1990).

$\mathrm{Na}$ literatura sobre sexualidade, gênero pode ser analisado sob o ponto de vista dos papeis sexuais e/ou da diferenciação sexo/gênero ou, em algumas das vertentes recentes, da crítica a tal diferenciação. Concomitantemente, essa categoria pode ser interpretada, enfatizando-se os aspectos representacionais ou o esquema das identidades, ou seja, a forma como se estabelece 
o sentimento individual ou coletivo de identidade (GROSSI, 1998). Sob outro ângulo, e possivelmente seja esse um dos aspectos mais instigantes, não há afluências em termos de se abordar sexualidade e gênero como distintos - e, destarte, não há consonância sobre as possíveis analogias entre ambos (ANDRADE, 2015; LOURO, 2004; VANCE, 1995).

\title{
3.3 Contribuições da teoria da representação social
}

Embora a teoria da Representação Social (RS) seja fluida e fronteiriça entre a sociologia e a psicologia social, possibilita-nos ampliar nosso entendimento em questão. Para isso, recorremos ao teórico que é referência nos estudos da RS, Serge Moscovici. De acordo com o pesquisador:

As representações sociais são conjuntos dinâmicos, seu status é o de uma produção de comportamentos e relações com o meio, o de uma ação que modifica uns e outros, e não o de uma reprodução [...], nem o de uma reação a um estímulo exterior determinado. [...] são sistemas que têm uma lógica própria e uma linguagem particular, uma estrutura de implicações que se referem tanto a valores como a conceitos [com] um estilo de discurso próprio. Não as consideramos como opiniões sobre nem imagens de, mas como teorias, como ciências coletivas. Sui generis, destinadas à interpretação e à construção da realidade. (MOSCOVICI, 2003, p.48).

Em relação à fluidez, mencionada anteriormente, e para ampliar a compreensão sobre RS, citamos a definição da estudiosa Denise Jodelet (2002, p. 22):

\begin{abstract}
As representações sociais são uma forma de conhecimento socialmente elaborado e compartilhado, com um objetivo prático, e que contribui para a construção de uma realidade comum a um conjunto social. A fluidez de conceituação da representação social, com seus múltiplos enunciados, é alvo fácil da crítica. Esta também ataca o fato de que a teoria propõe metodologias variadas e pouco amarradas. Moscovici costuma responder a tais críticas afirmando tratar-se de uma fluidez proposital, que visa permitir desenvolver a teoria e a criatividade dos pesquisadores, na medida em que o interesse maior seria a descoberta e não a verificação e a comprovação.
\end{abstract}

No sentido de articularmos os pensares dos teóricos mencionados e refletirmos sobre a incorporação das representações sociais dos/as professores/as - que podem comprometer ou inibir as ações humanas no cotidiano, já que há o condicionamento de papéis diferenciados para os sexos - esta realidade traz para a escola o desafio de descobrir e desenvolver criativamente novas formas de abordar e discutir com os/as alunos/as as questões que envolvem gênero e sexualidade no cotidiano da escola. Giroux e McLaren (1999, p. 143) salientam sobre a importância da linguagem na construção da experiência e subjetividade no espaço escolar, afirmando que está

intimamente relacionada ao poder, a linguagem não apenas posiciona professores e alunos, mas também funciona como veículo por meio do qual eles definem, mediatizam e compreendem suas relações uns com os outros e com a sociedade mais ampla.

Nesta dimensão, Freire (1992), na obra Pedagogia da Esperança, reafirma o que já dissera na Pedagogia do Oprimido, quando propôs um processo de alfabetização dialético defendendo o diálogo com as pessoas simples, não só como método, mas como uma forma democrática de inclusão. Anteriormente, Freire (1987, p. 20) afirmou que a possibilidade de libertação se amplia quando os sujeitos 'tomarem as suas histórias como reflexão e, 'destacando' seus problemas, enfrentarem-nos”, deste modo poderá ocorrer a transformação social. 
Sabemos que o enfrentamento sobre o tema gênero e sexualidade é urgente e mediar as práticas pedagógicas requer formação que proponha estabelecer relação entre o tema/objeto e o seu contexto, já que gênero é uma categoria relacional, na qual, ao se levar em conta os gêneros em presença, também se consideram as relações de poder, a importância da experiência, da subjetividade, do saber concreto. Da mesma maneira, a representação social não separa o sujeito social e o saber concreto do seu contexto, assim como a construção desse saber não pode se desvincular da subjetividade. Aqui vislumbramos como essas novas propostas se aproximam do pensamento complexo de que nos fala Morin (2000), abordagens apoiadas em redes de fatores que se comunicam e permitem dar sentido aos fenômenos que se quer estudar ou abordar.

Ao caminhar, em passos dialogantes nessas reflexões teóricas, compreendemos que o conceito de gênero é uma construção cultural e social e, como tal, sua representação e disseminação pelos meios comunicacionais e midiáticos, em diferentes linguagens, constroem ideais sociais, valores, estereótipos e preconceitos que acabam por incidir sobre as representações desejadas ou agrupadas. Nessa perspectiva, nos é possível compreender com Paulo Freire "que as pessoas se educam em relação, mediatizadas pelo mundo, ao mesmo tempo em que seus respectivos mundos culturais e sociais se transformam, mediatizados pelas próprias pessoas em relação" (FREIRE, 1987, p. 23). Tal concepção de educação traz como corolário a necessidade de se repensar e ressignificar a concepção de educador, dedicando particular atenção às relações e aos contextos que vão se criando, de modo a contribuir para a explicitação e elaboração dos sentidos (percepção, linguagens, significado e direção) que os sujeitos em relação constroem e reconstroem.

A partir dessas reflexões, o currículo e a didática utilizada nas práticas pedagógicas, mais do que um caráter lógico, terão uma função ecológica, ou seja, sua tarefa não será meramente a de configurar um referencial teórico de informações, mas a de fomentar a circulação de informações entre sujeitos, de modo que se auto-organizem em relação de reciprocidade entre si e com o próprio ambiente social.

\subsection{Nossos passos metodológicos}

A sociedade procura incessantemente modernizar-se tanto na esfera tecnológica quanto na científica, porém, no que tange a concepções e pré-conceitos, existem progressos e anacronismos, sobretudo quando o tema é gênero e sexualidade. Em face deste fato, questionamos se os/as educadores/as que lecionam na escola-campo estão aptos para trabalhar os conteúdos relacionados à sexualidade.

Por isso, para alcançar tal objetivo, optamos por um estudo de campo de caráter exploratório-descritivo. Conforme Gil (2008), as investigações dessa natureza têm como principal finalidade a descrição das características de uma dada comunidade ou fenômeno. Uma das principais singularidades deste tipo de investigação está no emprego de métodos padronizados de coleta de dados que, no caso específico desta pesquisa, foi um questionário com perguntas abertas e fechadas.

Assim, elegemos para este trabalho a abordagem qualitativa, a qual é analisada por Fazenda (2010) como a compreensão dos sujeitos na sua realidade, ou melhor, a descrição e entendimento destes sobre a sua experiência. De acordo com a autora, a pesquisa qualitativa, empregada na pesquisa em educação, possui o ambiente natural como geradora direta de dados, e do pesquisador como seu indissociável instrumento.

A pesquisa foi delineada em dois passos. Primeiro foi aplicado questionário, contendo 22 (vinte e duas) questões com perguntas abertas e fechadas, para ser respondido pelos professores dos anos iniciais do Ensino Fundamental, com o objetivo de analisarmos suas representações a respeito de gênero e sexualidade. No segundo passo, foi realizada a tabulação e sistematização dos 
dados coletados, o que possibilitou traçar o perfil do público por meio da quantificação do número de participantes, faixa etária, sexo, religião, escolaridade e posicionamentos diante das questões formuladas.

\subsection{Aligeirando nossos passos: resultados e reflexões}

A pesquisa elegeu os posicionamentos de professores/as dos anos iniciais do Ensino Fundamental da rede pública para refletir sobre a complexidade do tema gênero e sexualidade. Isso foi possível a partir da participação de 11 (onze) professores e professoras da escola-campo.

De acordo com os dados coletados, a maioria dos participantes declarou ser do gênero feminino (oito pessoas) contra 3 (três) do sexo masculino. Dos/as professores/as que participaram da pesquisa, constata-se que 4 (quatro) estão na faixa etária de 20 a 26 anos; 4 (quatro) entre 30 a 34; e 3 (três) acima dos 40 anos. No tocante à religião, os participantes responderam que 5 (cinco) são evangélicos, 4 (quatro) são católicos, 1 (um) espírita e houve 1 (uma) abstenção. Quanto à escolaridade, os participantes mencionaram que 6 (seis) possuem a graduação em Pedagogia, 1 (um) em Química e 1 (um) em Letras. Sendo que 3 (três) professores possuem o Ensino Médio.

Dada à complexidade do tema, os resultados trouxeram diversas possibilidades de análise e de cruzamentos de dados: possíveis diferenças de resposta entre sujeitos do gênero feminino e sujeitos do gênero masculino; diferenças entre professores/as da área de humanas com a de exatas; diferenças de resposta pautadas na orientação religiosa etc. No entanto, por conta do formato proposto para escrita deste texto, não haveria possibilidade de tal aprofundamento, assim como não seria possível a apresentação e análise de todos os dados coletados na pesquisa de campo. Desta forma, para este artigo, optamos por analisar 3 (três) itens do questionário aplicado aos/às professores/as que consideramos pontos nevrálgicos na investigação das representações dos/as educadores/as sobre gênero e sexualidade, com base na resposta dos sujeitos, a saber: 1) travestilidade; 2) homossexualidade masculina; 3) homossexualidade feminina.

O primeiro item (questão 12) interpela a respeito da existência de oposição, por parte professor, caso o docente do filho ou filha fosse travesti. A resposta obtida neste questionamento teve 3 (três) professores que disseram que sim, 6 (seis) disseram que não e 2 (dois)responderam não sei. Já na pergunta aberta, "por quê?", houve 5 (cinco) professores que se abstiveram em responder e 6 (seis) evidenciaram seus posicionamentos que estão dispostos no quadro a seguir:

Quadro 1 - Questão 12: Como pai ou mãe, você teria objeção se o professor de seu/sua filho/a fosse travesti?

\begin{tabular}{|l|}
\hline RESPOSTAS \\
\hline Não tenho filhos. \\
\hline Ensino meus filhos o respeito ao próximo em quaisquer circunstâncias. \\
\hline $\begin{array}{l}\text { Seria diferente de tudo que já vimos na sociedade. Algo, novo sim! Mas, que pode e deve ser compreendido } \\
\text { pela sociedade. }\end{array}$ \\
\hline Crio minha filha baseada nos conceitos bíblicos. \\
\hline $\begin{array}{l}\text { Porque se fosse assim, a própria existência dos homossexuais seria impossível, visto que a maior parte dos } \\
\text { professores é heterossexual. }\end{array}$ \\
\hline $\begin{array}{l}\text { Porque o professor é um profissional e como tal, deve contribuir para a formação do aluno, para respeitar e lidar } \\
\text { com as diferentes realidades que compõe a realidade. }\end{array}$ \\
\hline
\end{tabular}

Fonte: Questionário aplicado aos professores. 
Apesar da maioria das respostas dadas pelos professores ser de respeito à diversidade sexual e identidade de gênero, fica evidente o norteamento de cunho religioso em um posicionamento, em detrimento da dimensão educacional. Embora um/a professor/a não saiba como se posicionar devido a não ter filhos, nas práticas educativas ou possíveis diálogos que abordem gênero e sexualidade podem gerar conflitos ou rejeições por parte de todos os integrantes da escola, problematizando, sem individualizar, as questões dominantes da heterossexualidade sobre a travestilidade lá existente.

"E os próprios educadores podem renovar seu olhar sobre sua própria sexualidade e sobre como imaginam a sexualidade do outro, podendo navegar entre as fronteiras existentes entre nós e dentro de nós" (FLEURI, 2003, p. 28). Esta reflexão nos remete ao posicionamento posto por um/a professor/a em sua resposta: "Seria diferente de tudo que já vimos na sociedade. Algo, novo sim! Mas, que pode e deve ser compreendido pela sociedade". Apesar da aparente aceitabilidade contida na resposta, a palavra "diferente" denota a dificuldade de lidar com o não homogêneo, elegendo a heteronormatividade como modelo imposto para sexualidade e conservando preconceito.

Refletir sobre travestilidade é desafiador para a Educação por romper os limites do gênero, do corpo e da subjetividade numa dinâmica de construção e desconstrução de sujeitos que produzem sentido sobre os seus próprios corpos. O universo das/os travestis é caracterizado pelo magnetismo, irreverência, beleza, sexo, mas também pela consternação da sua condição, quer seja pela discriminação na família, na escola ou na sua rede social.

De acordo com Andrade (2015) e Benedetti (2005), este processo de transformação das/os travestis é quase um renascimento. Todavia este "nascer" igualmente não é apenas de gênero ou corpo, mas de toda proposição de subjetividade do sujeito que acontece diante de tais mudanças, como na forma de tratamento perante a sociedade - elas/es não desejam, por exemplo, ser reconhecidas/os pelo seu sexo biológico, mas sim pela sua identidade de gênero, inclusive empregando o nome social em todas as instâncias sociais.

Ponderando que a sociedade brasileira tem dificuldade de lidar com a diversidade, sobretudo com aqueles que irrompem com os protótipos hegemônicos de sexo-gênero, a comunidade LGBT passa por preconceitos e discriminações que aparecem de diversas maneiras: pela violência física, verbal ou psíquica; ou então pela expressão limitadora do exercício dos direitos de cidadania; pela negação do reconhecimento da diversidade sexual, e a naturalização do binarismo dos gêneros, apartando desta forma todos os sujeitos que vivenciam suas identidades de gênero com base em uma configuração diferente da dominante (ANDRADE, 2015; LOURO, 2009; QUARTIERO, 2009).

De acordo com Madureira e Branco (2007, p. 84), "os preconceitos correspondem a fronteiras simbólicas rígidas, construídas historicamente e com forte enraizamento afetivo que acabam por se construir em barreiras culturais entre grupos sociais e entre indivíduos". A resposta "Crio minha filha baseada nos conceitos bíblicos" revela a forte influência da herança judaico-cristã na nossa sociedade em que os dogmas religiosos são os orientadores a balizar representações que interferem na escola ou em qualquer outra esfera social. Acreditamos que os obstáculos para a superação de preconceitos ou qualquer tipo de discriminação serão intransponíveis e inalcançáveis enquanto a escola não for efetivamente laica. Neste sentido, o enfrentamento dialógico sobre as ressignificações das representações de gênero e sexualidade é imprescindível e urgente para o convívio democrático e plural.

Ao falar sobre o cotidiano das travestis na escola é imprescindível observar as condições em que elas estão inseridas já que muitas vezes o ambiente escolar se torna aversivo para a aprendizagem e o desenvolvimento da sociabilidade dos sujeitos "diferentes". Algumas cidades já permitem que as travestis utilizem o seu nome social nas escolas, no entanto elas querem mais que isso, que as escolas sejam um ambiente que possibilitem a elas uma condição de vida menos 
excludente ao invés de ser um dos primeiros locais onde irão aprender sobre as dificuldades de ser travesti.

\section{Figura A}

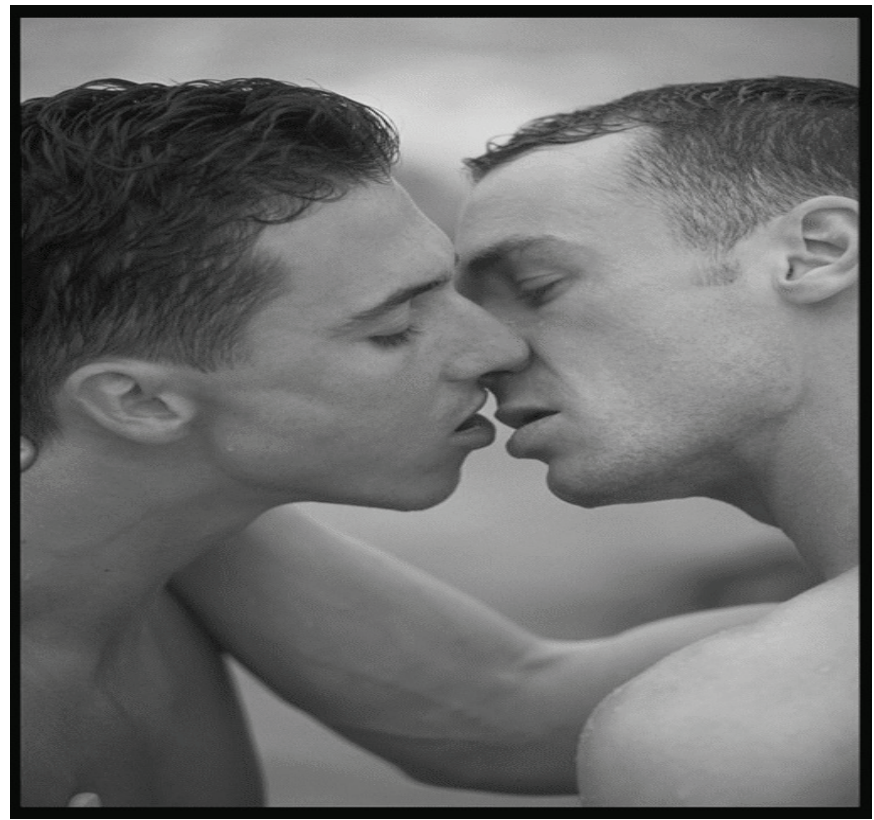

Fonte: Disponível em: <http://homofobianao.tumblr.com/>. Acesso em: 16 out. 2015.

\section{Figura B}

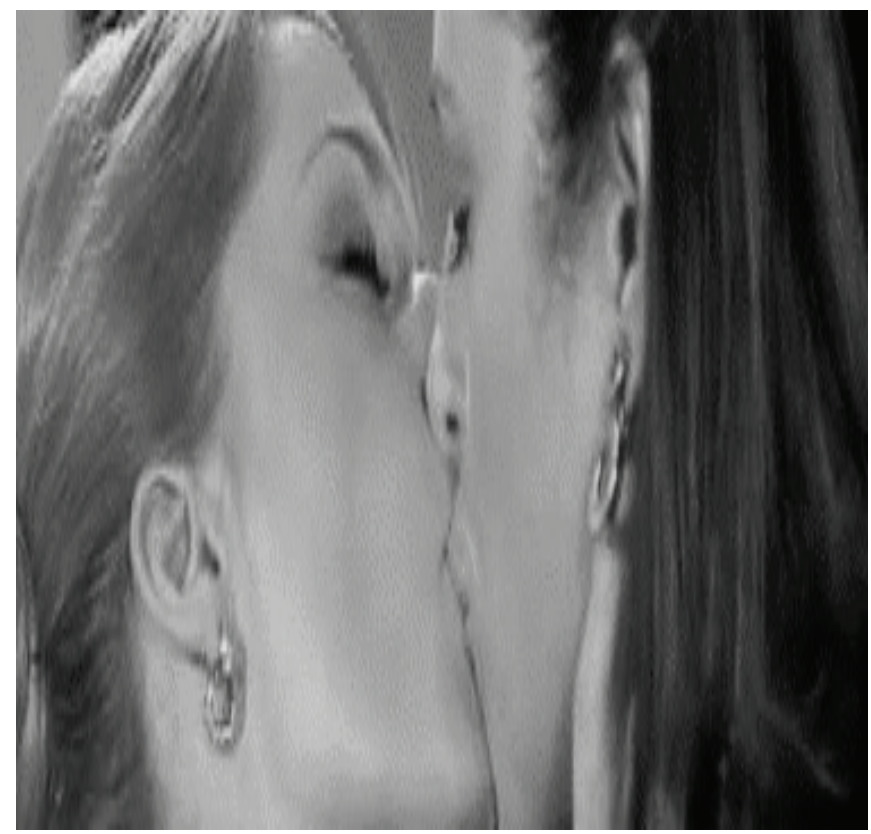

Fonte: Disponível em: <http://televisao.uol.com.br>. Acesso em: 13 out. 2015. 
Quadro 2 - Questões 19 (para a figura A) e 20 (para a figura B): Assinale a alternativa que mais se aproxima da sua reação ao ver uma cena como a retratada nas figuras:

\begin{tabular}{|l|c|c|}
\hline RESPOSTAS & Figura A & Figura B \\
\hline ( ) até aceito, mas depende do lugar & 2 & 3 \\
\hline ( ) é estranho & 1 & 1 \\
\hline ( ) incomoda & 2 & 2 \\
\hline ( ) choca & 1 & 1 \\
\hline ( ) é um desperdício & 1 & - \\
\hline ( ) é normal & 2 & 2 \\
\hline ( ) é pecado & 2 & 2 \\
\hline ( ) não é natural & 2 & 2 \\
\hline ( ) tenho nojo & - & - \\
\hline
\end{tabular}

Fonte: Questionário aplicado aos professores

Quanto às questões 19 (dezenove) e 20 (vinte) - vide figuras A e B e quadro 2 - havia espaço reservado para que os professores expressassem "outras reações" diferentes das indicadas no quadro apresentado. Entretanto, apenas dois professores externaram seu posicionamento repetindo suas respostas para ambas as questões: o/a primeiro/a ponderou que "neste caso até aceito, não só com casais homossexuais, mas também os casais heterossexuais", já o/a segundo/a respondeu que "na realidade, ainda não é natural para nossa sociedade". Questões como estas nos remetem à reflexão da resposta anterior, trazendo à tona a dificuldade de lidar com a diversidade sexual dos sujeitos. Deste modo, o vigor 'excludente' do preconceito está aportado também na premissa de que comumente os sujeitos não falam sobre eles e, assim, prosseguem fabricando e difundindo discriminações sem qualquer reflexão.

Cabe realçar aqui a emersão intensa e devastadora de preconceito e intolerância nas respostas. Os/as participantes se posicionaram abertamente contra as homossexualidades, evidenciando condutas segregacionistas e violentas em relação ao que eles/as consideram "diferente". Neste caso, a referência é sempre a heterossexualidade, de modo que todo sujeito que se difere desta orientação sexual é automaticamente rebaixado, rechaçado ou, melhor dizendo, infra-humanizado.

Assim, o preconceito pode ser entendido como um dos importantes mecanismos da manutenção da hierarquização entre os grupos sociais e da legitimação da inferiorização social na história de uma sociedade, o que muitas vezes se consolida como violência e ódio de uns sobre outros.

Diversas pesquisas sobre o preconceito, pensadas da esfera individual à social, asseguram a correlação entre a inferiorização social e os dispositivos de naturalização das desigualdades históricas (ADORNO; HORKHEIMER, 1973; CROCHIK, 2006; CAMINO et al., 2001). Se existe um componente contraditório no preconceito é que ele nos atrapalha de "ver" que "não vemos", isto é, ele opera encobertando motivos que legitimam determinados modos de subalternizações históricas, essencializadas por seus mecanismos. Em outras palavras, o preconceito nos obstrui o ato de discernir as fronteiras de nosso próprio entendimento da realidade.

Apesar de a hierarquização e a inferiorização se organizarem por meio de dinâmicas diferentes, são categoricamente complementares, e esta complementaridade tem sido empregada historicamente na conservação de desigualdades e no recrudescimento de processos de exclusão social, os quais podem incidir de maneiras muito diversas, passando desde o extermínio humano e a violência social até modos de inclusão subalternizadas, demonstrando, assim, o quão sério podem ser estes processos que assolam uma sociedade como um todo, e não somente alguns grupos sociais (RIZZATO, 2013; QUARTIERO, 2009). 
Mesmo os sujeitos participantes da pesquisa estando inseridos em uma escola, que tem o discurso de democracia e inclusão, seus posicionamentos não estão em consonância com a legislação educacional brasileira, com os Parâmetros Curriculares Nacionais e com as diretrizes estabelecidas para tratar a educação sexual na escola. Podemos observar que os programas oficiais são, muitas vezes, ignorados nas instituições escolares. Dentre vários motivos possíveis, destacamos a crença de muitos/as profissionais de que a discussão de gênero na escola é nociva para crianças e jovens, dificultando, assim, que atividades pedagógicas relacionadas a educação sexual cheguem nas salas de aula.

Nas sinalizações das opções "é estranho", "incomoda" e "choca" transparece a inabilidade e preconceito em relação à orientação sexual e/ou a identidade de gênero com base em um modelo hegemônico de sexualidade por parte dos/as participantes. Representações que estão para além dos muros da escola e influenciam o convívio dentro do espaço escolar, vitimando alunos homossexuais através da exclusão e discriminação. Já expressões como "é pecado" e "não é natural" estão permeadas de valores inculcados por preconceito justificado por dogmas religiosos. Segundo Vainfas (1992, p. 186), "não se pode negar o peso histórico de representações assaz negativas sobre o corpo e os prazeres nas sociedades ocidentais, em razão de uma extensa tradução de uma cultura judaico-cristã", que permeia as representações sobre gênero e sexualidade. A marcação na opção "é desperdício" remete ao modelo de sexualidade que estabelece apenas uma forma de vivenciar a masculinidade e a feminilidade, desconsiderando-se, assim, a orientação sexual e/ou a identidade de gênero, sob o rótulo de "falta de aproveitamento do natural". Essa representação pode conservar o estado de desigualdade e discriminação através da violência simbólica, e, também, como atos e atitudes homofóbicas (LOURO, 2009).

As colocações expressas na maioria das marcações feitas pelos professores estão carregadas de preconceitos, ambiguidades, incoerências e proibições que compõem suas representações a respeito de gênero e sexualidade. Expressões que registram e dão concretude às representações da percepção interpretativa do/a professor/a vindas do padrão da cultura ocidental, na qual a sociedade exige uma resposta nos moldes pré-estabelecidos, conforme a lei que rege as identidades hegemônicas. No entanto, a sexualidade comporta diversas possibilidades e, na prática pedagógica, urge a necessidade de se levar em conta a promoção da inclusão de todas as identidades de gênero e sexuais, que é um papel a ser desempenhado pela escola e um desafio para a formação de professores.

\section{4 | CONSIDERAÇÕES FINAIS}

Este artigo teve como pano de fundo, de um lado, a nossa participação no Programa Institucional de Bolsa de Iniciação à Docência (PIBID), através do subgrupo PEDiversidade, o que nos deu, inclusive, acesso à escola em que foi realizada a pesquisa. Por outro lado, foi norteado pelo viés da diversidade na abordagem das representações de professores/as sobre gênero e sexualidade.

Entendemos a complexidade das questões que remetem a gênero e sexualidade em uma sociedade que reproduz e conserva a não legitimação social e política de sujeitos que não pertencem ao "seleto" grupo das identidades hegemônicas. Manutenção vislumbrada nas representações dos/as professores/as em que foram destacadas colocações pautadas em modelos considerados dominantes, que ditam certas identidades como "normais" em detrimento de outras que marginalizam e excluem historicamente sujeitos sociais. E, ainda, consideram ser "pecado" a orientação voltada para a identidade homossexual. São expressões carregadas de preconceitos, ambiguidades, incoerências, estranhamentos, negações, proibições que compõem suas representações a respeito de gênero e sexualidade, que registram e dão concretude às representações ditadas pelo padrão da 
cultura ocidental e pelos valores judaico-cristãos que remetem a modelos pré-estabelecidos para identidades de gênero e sexuais.

Estes posicionamentos preconceituosos externados pelos/as professores/as podem condicionar, comprometer ou inibir as ações humanas no cotidiano escolar ou extraescolar. A submissão ao regime de subordinação pode instituir e conservar o estado de desigualdade (representacional) a que estão subjugados os grupos subalternizados (uma vez que ficam à disposição dos sentidos que Ihes são conferidos, de status sempre negativos). No contexto educacional, esta afirmativa suscita desafio emergencial na inserção do tema gênero e sexualidade nos currículos das licenciaturas, tanto na formação inicial, quanto na continuada de professores/as, visando o enfrentamento de posicionamentos homofóbicos no espaço escolar para descobrir e desenvolver criativamente novas formas de abordar e discutir com os alunos as questões que envolvem gênero e sexualidade no chão da escola. Consideramos que refletir sobre este tema nos processos de formação de professores é uma tarefa da qual não podemos nos eximir; muito pelo contrário: a luta deve ser constante.

Nesta dimensão, cabe mencionarmos que o mérito do subprojeto do PIBID do qual realizamos esta pesquisa está na possibilidade de fomentar debates entre estudantes em formação inicial e os já atuantes na docência, com base em temas sobre gênero e sexualidade na perspectiva da inclusão de todos/as, partindo-se do trabalho pedagógico crítico e criativo diante da diversidade sexual existente na sociedade brasileira.

Acreditamos que esta investigação sobre as representações de gênero e sexualidade é uma breve contribuição ao debate sobre o tema e instiga a continuidade, bem como o aprofundamento da temática, com o objetivo de fomentar a diversidade, o respeito e a prática de ações democráticas na escola. 


\section{Referências}

ADORNO, T.; HORKHEIMER, M. Temas básicos de sociologia. São Paulo: Cultrix, 1973.

ANDRADE, L. N. Travestis na escola: assujeitamento e resistência à ordem normativa. Rio de Janeiro: Metanoia, 2015.

BALESTRIN, P. A. Onde "está" a sexualidade?: representações de sexualidade num curso de formação de professoras. 2007. 196 f. Dissertação (Mestrado em Educação) - Universidade Federal do Rio Grande do Sul, Porto Alegre, 2007.

BENEDETTI, M. R. Toda feita: o corpo e o gênero das travestis. Rio de Janeiro: Garamond, 2005.

BRASIL. Lei n 9.394, de 20 de dezembro de 1996. Estabelece as diretrizes e bases da educação nacional. Diário Oficial da União, Brasília, DF, 23 dez. 1996.

CAMINO, L. et al. A face oculta do racismo no Brasil: uma análise psicossociológica. Revista Psicologia Política, n. 1, p. 13-36, 2001.

CROCHIK, J. L. Preconceito, indivíduo e cultura. 3. ed. São Paulo: Casa do Psicólogo, 2006.

FAZENDA, I. Metodologia da pesquisa educacional. São Paulo: Cortez, 2010.

FLEURI, R. M. Intercultura e educação. Revista Brasileira de Educação, Campinas, n. 23, p. 23-35, maio/jun./ jul./ago. 2003.

FOUCAULT, M. História da sexualidade I: a vontade de saber. Rio de Janeiro: Graal, 2007.

FREIRE, P. Pedagogia do oprimido. Rio de Janeiro: Paz e Terra, 1987.

Pedagogia da esperança: um reencontro com a pedagogia do oprimido. Rio de Janeiro: Paz e Terra, 1992.

FREITAS, H. C. L. de. A (nova) política de formação de professores: a prioridade postergada. Revista Educação e Sociedade, Campinas, v. 28, n. 100, p. 1203-1230, out. 2007. Edição especial.

GARCIA, O. A. Marcas da experiência na formação docente em gênero e diversidade sexual, um olhar sobre o curso "Gênero e Diversidade na Escola" (GDE). 2015. 162 f. Dissertação (Mestrado em Educação)- Faculdade de Educação da Universidade de São Paulo, São Paulo, 2015.

GIL, A. C. Métodos e técnicas de pesquisa social. São Paulo: Atlas, 2008.
GIROUX, H. A.; McLAREN, P. Formação do professor como uma contra esfera pública: a pedagogia radical como uma forma de política cultural. In: SILVA, T. T. da; MOREIRA, A. F. (Org.). Currículo, cultura e sociedade. São Paulo: Cortez, 1999. p. 125-154.

GROSSI, M. P. Identidade de gênero e sexualidade. Antropologia em primeira mão, Florianópolis: PPGAS/ UFSC, n. 24, 1998.

INSTITUTO BRASILEIRO DE GEOGRAFIA E ESTATÍSTICA. Pesquisa nacional por amostra de domicilios. Brasília, DF, 2013. Disponível em: <http:// www.ibge.gov.br/home/estatistica/populacao/trabalhoerendimento/pnad2013/default.shtm>. Acesso em: 22 set. 2014.

JODELET, D. (Org.). Representações sociais. Rio de Janeiro: Eduerj, 2002.

LOURO, G. L. Gênero, sexualidade e educação: uma perspectiva pós-estruturalista. 2. ed. Petrópolis: Vozes, 1998.

Heteronormatividade. In: JUNQUEIRA, R. D. (Org.). Diversidade sexual na educação: problematizações sobre homofobia nas escolas. Brasília, DF: MEC; Unesco, 2009. p. 85-93.

Um corpo estranho: ensaios sobre sexualidade e teoria queer. Belo Horizonte: Autêntica, 2004.

MADUREIRA, A. F. A.; BRANCO, A. M. Identidades sexuais não-hegemônicas: processos identitários e estratégias para lidar com o preconceito. Psicologia: Teoria e Pesquisa, v. 23, n. 1, p. 81-90, 2007.

MEYER, D. E. Gênero e educação: teoria e prática. In: LOURO, G. L.; NECKEL, J. F.; GOELLNER, S. V. (Org.). Corpo, gênero e sexualidade: um debate contemporâneo na educação. Petrópolis: Vozes, 2003.

MORIN, E. Epistemologia da complexidade. In: SCHNITMAN, D. F. (Org.). Novos Paradigmas, cultura e subjetividade. Porto Alegre: Artes Médicas, 2000.

MOSCOVICI, S. Representações sociais: investigações em psicologia social. Petrópolis: Vozes, 2003.

OLIVEIRA, K. F. Gênero e sexualidade na educação de jovens e adultos: um estudo de caso. 2010. 119 f. Dissertação (Mestrado em Educação em Ciências) - Universidade Federal do Rio Grande do Sul, Porto Alegre, 2010.

QUARTIERO, E. T. A diversidade sexual na escola: produção de subjetividade e políticas públicas. 2009. $145 \mathrm{f}$. Dissertação (Mestrado em Psicologia Social)- Universidade Federal do Rio Grande do Sul, Porto Alegre, 2009. 
ENTRE OS DITOS E OS INTERDITOS | Jonas Junior, Mônica Fernandes e Sandra Faustino

RIZZATO, L. K. Percepções de professores/as sobre gênero, sexualidade e homofobia: pensando a formação continuada a partir de relatos da prática docente. 2013. 278 f. Dissertação (Mestrado em Educação)- Faculdade de Educação da Universidade de São Paulo, São Paulo, 2013.

SANTOS, L. N. Currículo de licenciatura em educação física e politicas educacionais de gênero e de diversidade sexual: articulações (im)possíveis. 2014. 160 f. Tese (Doutorado em Educação)- Universidade Federal do Rio Grande do Sul, porto Alegre, 2014.

SCOTT, J. Gênero: uma categoria útil de análise histórica. Educação \& Realidade, Porto Alegre, v. 15, n. 2, p. 5-72, jul./dez. 1990. Número especial Mulher e Educação.

SEFTON, A. P. Prática docente e socialização escolar para as diferenças: um estudo sobre estratégias de transformação da ordem em gênero e sexualidade. 2013. 195 f. Tese (Doutorado em Educação)- Faculdade de Educação da Universidade de São Paulo, São Paulo, 2013.

VAINFAS, R. Casamento, amor e desejo no ocidente cristão. São Paulo: Ática, 1992.
VANCE, C. S. A antropologia redescobre a sexualidade: um comentário teórico. Physis - Revista de Saúde Coletiva, Rio de Janeiro: IMS/UERJ, v. 5, n. 1, p. 7-31, 1995.

VIANNA, C. P.; UNBEHAUM, S. O gênero nas políticas públicas de educação no Brasil: 1988-2002. Cadernos de Pesquisa, v. 34, n. 121, p. 77-104, jan./abr. 2004.

WEEKS, J. O corpo e a sexualidade. In: LOURO, G. L. (Org.). O corpo educado: pedagogias da sexualidade. Belo Horizonte: Autêntica, 2001.

ZARTH, S. M. Temas transversais no ensino fundamental: educação para a saúde e orientação sexual. 2013. 119 f. Tese (Doutorado em Educação)- Pontifícia Universidade Católica do Rio Grande do Sul, Porto Alegre, 2013.

\section{SITES}

Homofobia não!. Disponível em: <http://homofobianao. tumblr.com>. Acesso em: 16 out. 2015.

Portal UOL. Disponível em: <http://televisao.uol.com.br >. Acesso em: 13 out. 2015. 